\title{
Comparison of efficacy of intravenous dexmedetomidine with intravenous ketamine in allaying procedural discomfort during establishment of subarachnoid block
}

\author{
S Parthasarathy ${ }^{1^{*}}$, AJ Charles ${ }^{2}$, DR Singh , VR Hemanth Kumar $^{3}$ \\ Associate Professor ${ }^{1}$, Assistant Professor ${ }^{2}$, Professor, Mahatma Gandhi Medical College and \\ Research Institute, Puducherry, India.
}

\begin{abstract}
Background: Procedural discomfort is experienced by patients during the establishment of subarachnoid block even after good preoperative counseling and adequate premedication. The fear of needle prick, back pain during and after subarachnoid injection are becoming the leading causes for patient refusal to spinal anaesthesia. To enhance comfort and to overcome the denial, procedural sedation that would provide good analgesia, faster recovery and amnesia is inevitable.

Materials and methods: Patients with ASA status I and II posted for elective surgeries under subarachnoid block were premedicated with midazolam $0.05 \mathrm{mg} / \mathrm{kg}$ and pre-loaded with $10 \mathrm{ml} / \mathrm{kg}$ ringer lactate solution. They were randomized into 2 groups of 30 each. Group D received dexmedetomidine $1 \mathrm{mcg} / \mathrm{kg}$ bolus over $10 \mathrm{~min}$, group $\mathrm{K}$ received ketamine $0.3 \mathrm{mg} / \mathrm{kg}$ intravenously. University of Michigan sedation score, ease of positioning, prick response, verbal response, hallucinations, recall of procedure and patient satisfaction were evaluated.

Results: Both the drugs produced adequate sedation for performing subarachnoid block, UMSS score response to needle prick was comparable between them. Significant difference was observed during positioning the patient for subarachnoid block. Patients sedated with dexmedetomidine were able to position themselves without any help whereas patients sedated with ketamine required one or two persons help. In maintaining verbal response during the procedure both the drugs showed significant difference between them. In group $\mathrm{D}$, most of the patients maintained the verbal response from immediately after bolus to throughout the study. Whereas in group $\mathrm{K}$, no patient responded to verbal command after bolus up till $3 \mathrm{~min}$ and majority of them (40\%) regained verbal response only at $4 \mathrm{~min}$ after bolus injection. There were no hallucinations and no recall of events in both groups. Except one patient in group D, all the patients were satisfied and willing to undergo subarachnoid block if need arises.
\end{abstract}

Conclusion: We conclude that both ketamine and dexmedetomidine provided adequate sedoanalgesia for performing subarachnoid block. Dexmedetomidine was advantageous in terms of maintaining verbal response and ability to positioning themselves.

Keywords: subarachnoid block; sedation; dexmedetomidine; ketamine

\section{Introduction}

Procedural discomfort is experienced by patients during the establishment of subarachnoid block

*Correspondence: S Parthasarathy

E mail: painfreepartha@gmail.com

iD 0000-0002-3808-6722

Received: 09/03/2017

Accepted: 14/05/2017

DOI: $10.4038 /$ slja.v25i2.8222

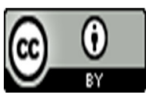

even after good preoperative counseling and adequate premedication. This could be due to multiple reasons such as cold operating environment, new people, positioning, and obviously the procedure itself. ${ }^{1}$ The fear of needle prick and the fear for back pain during and after subarachnoid injection is becoming the leading cause for the patient denial to undergo the procedure. ${ }^{2}$ To enhance comfort and to overcome the denial, procedural sedation that would provide good analgesia, faster recovery and amnesia is necessary. ${ }^{3}$ There are many studies with different drugs including ketamine used to provide adequate sedation for performing subarachnoid blockade. ${ }^{4-6}$ Use of 
dexmedetomidine has not been investigated or compared for providing sedation during the performance of spinal anaesthesia much. Hence we decided to compare the sub anaesthetic dose $0.3 \mathrm{mg} / \mathrm{kg}$ ketamine with dexmedetomidine at $1 \mu \mathrm{g} / \mathrm{kg}$ over ten minutes for allaying discomfort while performing subarachnoid blockade.

\section{Methodology}

After the approval from hospital ethics committee (IHEC-MGMCRI-faculty 2014/32), a randomized double blind prospective study was conducted in sixty patients aged between 18 to 60 years of ASA status I and II posted for elective surgeries under subarachnoid block. Patients with compromised cardiovascular or respiratory function, bleeding diathesis and pregnancy were excluded from the study. Procedures involving epidural placement were also excluded. After obtaining informed consent, premedication was with oral diazepam $10 \mathrm{mg}$ in the night and $10 \mathrm{mg}$ on the morning of the surgery. After accepted fasting, all patients were premedicated with midazolam $0.5 \mathrm{mg} / \mathrm{kg}$ and pre-loaded with 10 $\mathrm{ml} / \mathrm{kg}$ ringer lactate solution in the preoperative holding area. The patients were shifted to operation room table and the baseline haemodynamic parameters were recorded. The patients were randomized to one of 2 groups by closed envelope technique. Group $\mathrm{K}$ received ketamine $0.3 \mathrm{mg} / \mathrm{kg}$, Group $\mathrm{D}$ received dexmedetomidine at a dose of $1 \mu \mathrm{g} / \mathrm{kg}$ over tenminute infusion. After opening the envelope, the study drug was prepared such that ketamine at a dose of $0.3 \mathrm{mg} / \mathrm{kg}$ was diluted in a $10 \mathrm{ml}$ syringe and dexmedetomidine was diluted in a $100 \mathrm{ml}$ normal saline bottle. Each patient received a $100 \mathrm{ml}$ saline infusion over $10 \mathrm{~min}$ after that a $10 \mathrm{ml}$ of injection bolus was given. For patients in Group $\mathrm{K}$ received plain $100 \mathrm{ml}$ normal saline infusion and at the end of the infusion, ketamine $0.3 \mathrm{mg} / \mathrm{kg}$ was given. For patients in group $\mathrm{D}$, dexmedetomidine $1 \mu \mathrm{g} / \mathrm{kg}$ was added in $100 \mathrm{ml}$ saline and given over $10 \mathrm{~min}$ and $10 \mathrm{ml}$ plain saline bolus was given at the end of the infusion. This drug preparation was done by a separate anaesthesiologist who was not involved in the study. The patient identification was written on a slip and put back into envelope and sealed. By this way, the observer was blinded to the drugs given to the patient. The person doing the procedure and monitoring along with the patient was blinded to the drug. The study parameters were carefully evaluated. University of Michigan sedation score (Table 1) was noted 3 minutes after giving the drug and patient was put into the lateral position.

Ease of positioning for subarachnoid block (while turning the patient to the lateral position) was assessed by a three-point scale (1. Patient turned on his own, 2. Patient turned with the help of one person, 3. Patient turned with the help of more than one person). The parameters monitored (heart rate, mean arterial blood pressure, oxygen saturation, respiratory rate and sedation score) were recorded every 3 minutes for 15 minutes. With aseptic precautions, subarachnoid block was performed using $25 \mathrm{~g}$ Quincke spinal needle without local infiltration. The desired volume of bupivacaine $0.5 \%$ heavy was injected intrathecally. Response to spinal needle insertion was noted and graded by 4-point score. Then the patient was placed in supine position for surgery. Apnoea, airway obstruction and involuntary movements if present were noted. Time interval between the study drug injection and response to verbal commands (defined as precisely answering questions about name, date of birth and home address) was noted in minutes. Complications like vomiting, hallucinations, if occurred were noted. In recovery area, when patient was fully awake, patient recall of the subarachnoid block procedure was noted as yes or no. The patient satisfaction was assessed by asking whether he or she would undergo spinal procedure again, if the need arise.

\section{Statistical analysis}

With an expected rise of $20 \%$ better cooperation from patients receiving dexmedetomidine and a power of 0.8 , a total of 48 patients were needed. Covering for the probable drop outs, we recruited a total of sixty patients in the study. Demographic profile was expressed as mean \pm SD. Haemodynamic parameters, $\mathrm{SpO}_{2}$, respiratory rate and verbal response were assessed by one way ANOVA. Sedation score, ease of positioning and prick response were compared by nonparametric Mann Whitney $U$ test. Hallucinations, recall of procedure and patient satisfaction were assessed by Chi square test. A $p$ value of $<0.05$ was considered statistically significant.

\section{Results}

The demographic profile was comparable between the groups, which was statistically confirmed. Demographic profile is summarized in Table 1. 
Table 1: Demographic variables

\begin{tabular}{|l|l|l|l|l|}
\hline Study variables & $\begin{array}{l}\text { Dexmedetomidine } \\
\text { Group (Group-D) } \\
\mathrm{n}=\mathbf{3 0}\end{array}$ & $\begin{array}{l}\text { Ketamine } \\
\text { Group } \\
\text { (Group-K) } \\
\mathrm{n}=\mathbf{3 0}\end{array}$ & $\begin{array}{l}\mathrm{p}- \\
\text { value } \\
\mathbf{s}\end{array}$ \\
\hline Age (years) & $36.93 \pm 12.65$ & $38 \pm 10.3$ & 0.722 \\
\hline \multirow{2}{*}{ Weight (kg) } & $60.57 \pm 12.25$ & $\begin{array}{l}54.83 \pm \\
12.617\end{array}$ & 0.079 \\
\hline \multirow{2}{*}{ Sex } & Male & 22 & 15 & 0.055 \\
\cline { 2 - 5 } & Female & 8 & 15 & \\
\hline
\end{tabular}

No statistically significant difference was found in UMSS sedation score $(\mathrm{p}=0.255)$ between the groups. Both the drugs produced adequate and effective sedation for performing subarachnoid blockade. $80 \%$ of patients in group D and $73 \%$ of patients in group $\mathrm{K}$ were found to be minimally sedated. Only $6.7 \%$ of patients in group $\mathrm{K}$ were found to be deeply sedated but no patients were deeply sedated in group D (Figure 1).

Figure 1: Sedation score between the groups.

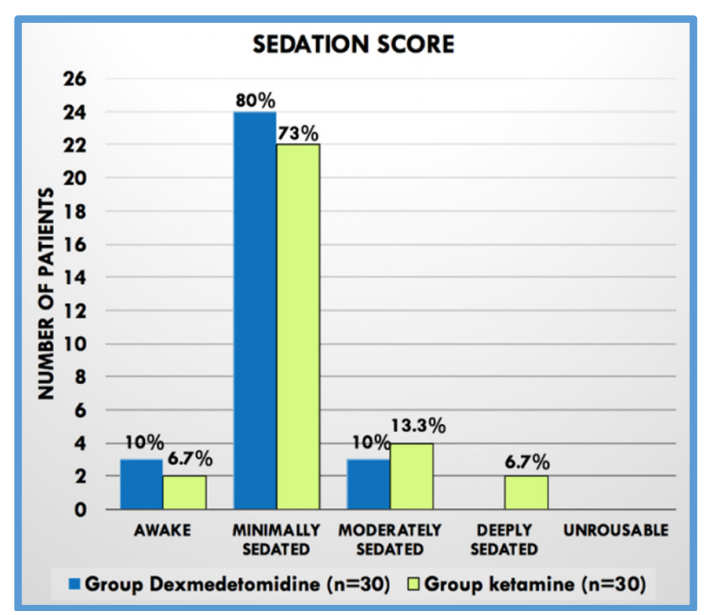

With regard to the ease of positioning, $80 \%$ of patients in group $\mathrm{D}$ were able to turn themselves without anyone's help whereas only $20 \%$ in group $\mathrm{K}$ were able to turn themselves. Thus in ketamine group, majority (67\%) of them required other persons help for positioning for subarachnoid blockade in which $17 \%$ of patients required assistance of two persons (Figure 2). Ease of positioning was significantly different between the three groups $(\mathrm{p}<001)$.
Figure 2: Ease of positioning between groups.

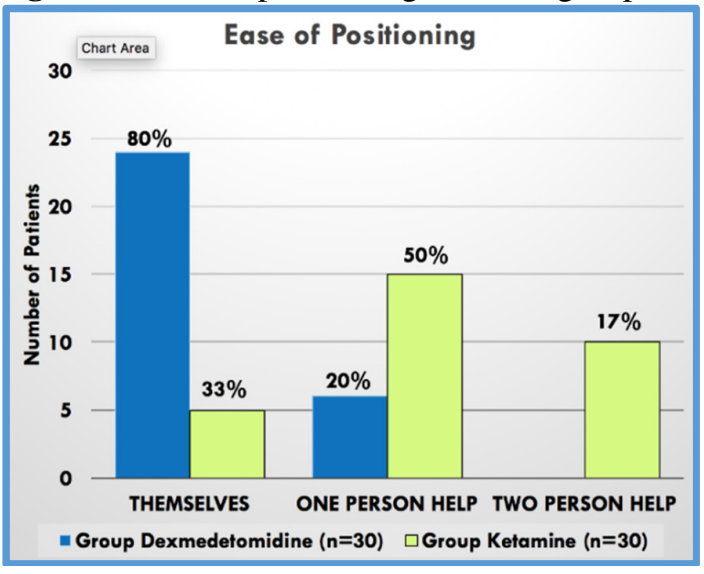

When the response to prick was assessed 56.7\% of patients in dexmedetomidine group showed no response to needle prick and only $3.3 \%$ showed gross movements. In group K, $40 \%$ showed no response but $10 \%$ showed gross movement during needle prick. But needle prick response scores were not statistically significant. $(\mathrm{p}=0.254)$ (Figure 3$)$.

Figure 3: Needle prick response between the groups.

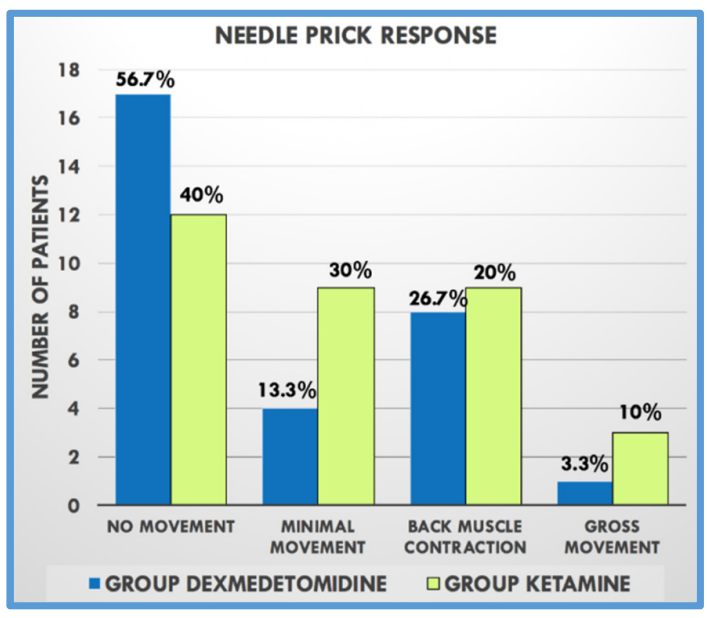

Early verbal response was elucidated in group D, i.e., $70 \%$ of the patients were able to maintain verbal response and the rest regained verbal response within $3 \mathrm{~min}$ after turning supine. In ketamine group, no patients were responding to verbal commands up till 2 min after turning patient supine. At 2 mins, only 3 patients were responding and about $40 \%$ of them were responding to commands at 3-4mins time. $3-5 \%$ of them responded only at $15 \mathrm{~min}$ after subarachnoid blockade. The Fischer Exact test 
was done to decipher the $\mathrm{p}$ value as 0.01 . Hence it is clear that the level of verbal response was definitely better in the dexmedetomidine group.

Figure 4: Verbal response between the groups.

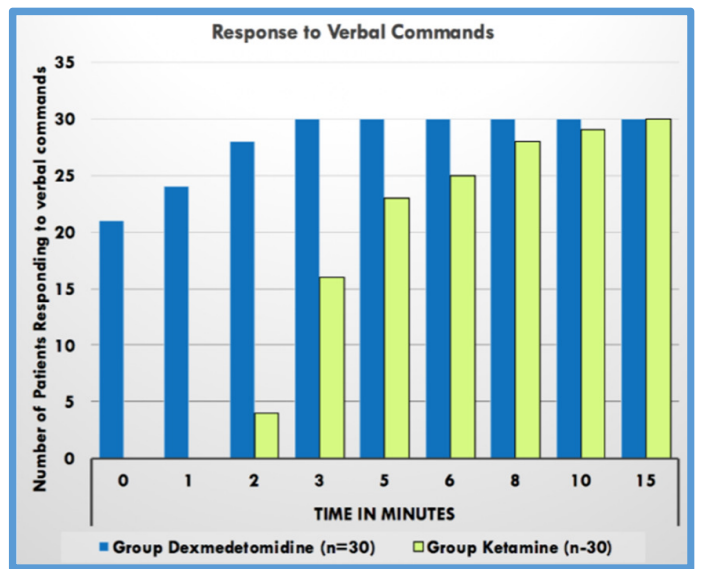

None of the patients in both groups could recall spinal needle prick. No patients encountered any haemodynamic imbalance or respiratory depression. No patients of either group had any hallucinations or cognitive disturbances.

All the patients in both groups except one patient in dexmedetomidine group were satisfied with the spinal procedure and were willing to undergo it again, if the need arises.

\section{Discussion}

Various drugs had been used for sedation during neuraxial block. Many drugs such as midazolam, propofol, opioids, sevoflurane, and ketamine either alone or in combination are being used. ${ }^{6}$ Excessive sedation before administration of spinal anaesthesia may make positioning difficult. Propofol usage produces excess sedation to complicate positioning in spinal anaesthesia. ${ }^{7}$ Even though remifentanil produced less sedation during pre-procedural sedation than propofol the study was not limited to spinal anaesthesia alone. ${ }^{8}$ Hemant Kumar et $\mathrm{al}^{9}$ found that $0.3 \mathrm{mg} / \mathrm{kg}$ bolus dose of ketamine produced safe and adequate sedation for performing subarachnoid blockade without major haemodynamic instability. They have not reported hallucinations to a significant extent as they combined with midazolam. Patki et al have shown midazolam and propofol have equi sedative properties during spinal anaesthesia. ${ }^{7}$ Kilic et $\mathrm{al}^{10}$ found that dexmedetomidine at dose
$1 \mu \mathrm{g} / \mathrm{kg}$ followed by $0.5 \mu \mathrm{g} / \mathrm{kg}$ infusion produces adequate sedation for 50 patients during ERCP with stable haemodynamics. Hence we decided to compare the sedation quality for these two drugs by giving a single bolus dose while performing subarachnoid block.

$80 \%$ of patients in dexmedetomidine group and $73.3 \%$ in ketamine group had UMSS score of 1 which is satisfactory for performing subarachnoid block. In our study we found that both dexmedetomidine and ketamine produced adequate and comparable sedation in terms of UMSS score. Shah et $\mathrm{al}^{11}$ have also observed adequate and comparable levels of sedation in spinal analgesia while using either propofol or dexmedetomidine. But we have ketamine and dexmedetomidine to state that the latter produced lesser sedation. Even though sevoflurane produced dose-related sedation, more satisfaction, and a speedier recovery from sedation than midazolam, it was responsible for excessive theatre pollution and patient excitement. $^{12}$ In our study, ketamine and dexmedetomidine showed significant difference in terms of ease of positioning and maintenance of verbal responses. A majority of patients in dexmedetomidine group were able to position themselves without help. Jia Song et $\mathrm{al}^{13}$ in their study of dexmedetomidine for sedation in regional anaesthesia have found that an infusion of $0.25 \mu \mathrm{g} / \mathrm{kg}$ after a bolus of $1 \mu \mathrm{g} / \mathrm{kg}$ produced effective sedation without cardiac side effects but they have not studied the ease of positioning which matters the most with regard to administration of spinal anaesthesia. In context to maintaining verbal response after bolus dose in dexmedetomidine group $70 \%$ of the patients had no loss of verbal response. Whereas in ketamine group no patient responded to verbal command after bolus till $3 \mathrm{~min}$ of time and majority of them (40\% of the patients) regained verbal response only at $4 \mathrm{~min}$ after bolus injection. Similarly, Kilicet $\mathrm{al}^{10}$ found that during procedural sedation with dexmedetomidine conscious status of the patients were preserved throughout which attributed to better satisfaction. Here we attribute that maintenance of conscious status without loss of verbal response in dexmedetomidine group was very helpful during positioning the patients and also while assessing the level of subarachnoid block during the initial crucial 3 mins after injection. Hence in our study, this intact verbal response in group D, was very useful in assessment of spinal anaesthesia. 
There was no significant haemodynamic instability in both the groups which was similar to the findings of Hemanth Kumar et $\mathrm{al}^{9}$ during ketamine sedation probably because of subanaesthetic single bolus dosing. Kilic et $\mathrm{al}^{10}$ also observed similar results during sedation with dexmedetomidine. No side effects or hallucination was noticed in either group.

All patients in both the groups were satisfied with the sedation during subarachnoid blockade. We also looked further, whether patients who moved due to spinal needle prick remembered the event after surgery. There was no recall of spinal procedure in any of the groups in spite of back muscle contraction or movement. In both groups, majority of the patients did not show any response to needle insertion. This could be the reason for good patient satisfaction in both groups and due to this effect; they were willing to undergo spinal procedure again, if the situation arises. Recall of noxious spinal needle insertion was not present in both groups possibly due to a combined analgesic amnesic property of both drugs. Probably this is the first study which describes dexmedetomidine with advantages of suitable sedation with maintenance of conscious status in patients undergoing spinal anaesthesia. In our patients, there was no significant haemodynamic disturbance in either group which implicates that the dosage of both drugs mattered in the study. OK et al $^{14}$ have demonstrated effective sedation with minimal side effects with a loading dose of $1 \mu \mathrm{g} / \mathrm{kg}$. There is a study ${ }^{15}$ which describes a prolongation of spinal anaesthesia with intravenous dexmedetomidine which we have not taken as our outcome variable. The limitations of this study are a smaller sample size and fixed doses of sedative drugs.

\section{Conclusion}

We conclude that both ketamine and dexmedetomidine provide adequate sedation for performing subarachnoid block. Patients who received dexmedetomidine were more conscious with a better verbal response. This was advantageous in terms of positioning themselves without help and a better cooperation with the anaesthesiologist for assessing the subarachnoid block. With the dosage of $0.3 \mathrm{mg} / \mathrm{kg}$ of ketamine or $1 \mu \mathrm{g} / \mathrm{kg}$ of dexmedetomidine, the observed side effects were insignificant in both groups.

\section{References}

1. Liu SS, McDonald SB. Current issues in spinal anesthesia. Anesthesiology. 2001; 94:888-906. https://doi.org/10.1097/00000542-200105000$\underline{00030}$

2. Pollock JE, Neal JM, Burkhead D, Polissar N. Sedation during Spinal Anesthesia. Anesthesiology.2000;93:728-734. https://doi.org/10.1097/00000542-200009000$\underline{00022}$ PMid:10969306

3. De Andres J, Valia JC, Gil A, Bolinches R. Predictors of patient satisfaction with regional anaesthesia. RegAnesth. 1995;20:498-505 PMid:8608068

4. Höhener D, Blumenthal S, Borgeat A. Sedation and regional anaesthesia in the adult patient. $\mathrm{Br} \mathrm{J}$ Anaesth.2008:100(1):8-16 https://doi.org/10.1093/bja/aem342 PMid:18070783

5. Kaur S, Gupta KK, Singh A, Sunita, Baghla N. Arousal from sedation in lower abdominal surgeries under spinal anesthesia: Comparison between dexmedetomidine and clonidine. Anesth EssaysRes2016;10:98-103 https://doi.org/10.4103/0259-1162.164741 PMid:26957699 PMCid:PMC4767104

6. Attri JP, Gupta KK, Khetarpal R. Emerging trends of sedation during regional anesthesia. Anaesth Pain \& Intensive Care 2015; 19(4):527-532.

7. Patki A, Shelgaonkar VC. A comparison of equisedative infusions of propofol and midazolam for conscious sedation during spinal anesthesia A prospective randomized study. J AnaesthesiolClinPharmacol. 2011;27:47-53. PMid:21804706 PMCid:PMC3146158

8. Mingus ML, Monk TG, Gold MI, Jenkins W, Roland C. Remifentanil versus propofol as adjuncts to regional anesthesia. J ClinAnesth. 1998;10:46-53.

https://doi.org/10.1016/s0952-8180(97)00220-1

9. Hemanth Kumar VR, Athiraman UK, Jahagirdar SM et al. Comparison of efficacy of three subanesthetic doses of ketamine in allaying procedural discomfort during establishment of subarachnoid block: A randomized double-blind trial. Saudi J Anaesth. 2015;9:55-9. https://doi.org/10.4103/1658-354X.146307 PMid:25558200 PMCid:PMC4279351

10. Kilic N, Sahin S, Aksu H, et al. Conscious Sedation for Endoscopic Retrograde Cholangiopancreatography: Dexmedetomidine Versus Midazolam. The Eurasian Journal of Medicine.2011;43(1):13-17.

https://doi.org/10.5152/eajm.2011.03 PMid:25610153 PMCid:PMC4261372

11. Shah PJ, Dubey KP, Sahare KK, Agrawal A. Intravenous dexmedetomidine versus propofol for intraoperative moderate sedation during spinal anesthesia: A comparative study. J 
Parthasarathy et al. Sri Lankan Journal of Anaesthesiology: 25(2):76-81(2017)

AnaesthesiolClinPharmacol 2016;32:245-9. https://doi.org/10.4103/0970-9185.168172

12. Ibrahim AE, Ghoneim MM, Kharasch ED, et al. Speed of recovery and side-effect profile of sevoflurane sedation comparedwith midazolam. Anesthesiology 2001; 94: 87-94. https://doi.org/10.1097/00000542-200101000$\underline{00018}$ PMid: 11135727

13. Song J, Kim WM, Lee SH, Yoon MH. Dexmedetomidine for sedation of patients undergoing elective surgery under regional anesthesia. Korean Journal of Anesthesiology. 2013;65(3):203-208.

https://doi.org/10.4097/kjae.2013.65.3.203

PMid:24101953 PMCid:PMC3790030

14. Ok HG, Baek SH, Baik SW et al. Optimal dose of dexmedetomidine for sedation during spinal anesthesia. Korean Journal of Anesthesiology. 2013;64(5):426-431.

https://doi.org/10.4097/kjae.2013.64.5.426

PMid:23741565 PMCid:PMC3668104

15. Kaya FN, Yavascaoglu B, Turker $G$ et al. Intravenous dexmedetomidine, but not midazolam, prolongs bupivacaine spinal anesthesia. Can J Anaesth. 2010;57:39-45 https://doi.org/10.1007/s12630-009-9231-6 PMid:20039221 